\title{
A new option for early breast cancer patients previously irradiated for Hodgkin's disease: intraoperative radiotherapy with electrons (ELIOT)
}

\author{
Mattia Intra1 , Oreste Gentilini ${ }^{1}$, Paolo Veronesi ${ }^{1}, 2$, Mario Ciocca ${ }^{3}$, Alberto Luini ${ }^{1}$, Roberta Lazzari ${ }^{4}$, \\ Javier Soteldo1, Gabriel Farante1, Roberto Orecchia ${ }^{2,4}$ and Umberto Veronesi ${ }^{1}$
}

1Department of Breast Surgery, European Institute of Oncology, Milan, Italy
2University of Milan, School of Medicine, Milan, Italy
3Medical Physics Unit, European Institute of Oncology, Milan, Italy
4Department of Radiotherapy, European Institute of Oncology, Milan, Italy

Corresponding author: Mattia Intra, mattia.intra@ieo.it

Received: 4 Feb 2005 Revisions requested: 18 Mar 2005 Revisions received: 28 Jun 2005 Accepted: 21 Jul 2005 Published: 16 Aug 2005

Breast Cancer Research 2005, 7:R828-R832 (DOI 10.1186/bcr1310)

This article is online at: http://breast-cancer-research.com/content/7/5/R828

(c) 2005 Intra et al. licensee BioMed Central Ltd.

This is an Open Access article distributed under the terms of the Creative Commons Attribution License (http://creativecommons.org/licenses/by/ 2.0), which permits unrestricted use, distribution, and reproduction in any medium, provided the original work is properly cited.

\begin{abstract}
Introduction Patients who have undergone mantle radiotherapy for Hodgkin's disease (HD) are at increased risk of developing breast cancer. In such patients, breast conserving surgery (BCS) followed by breast irradiation is generally considered contraindicated owing to the high cumulative radiation dose. Mastectomy is therefore recommended as the first option treatment in these women.
\end{abstract}

Methods Six patients affected by early breast cancer previously treated with mantle radiation for HD underwent BCS associated with full-dose intraoperative radiotherapy with electrons (ELIOT).
Results A total dose of 21 Gy (prescribed at $90 \%$ isodose) in five cases and 17 Gy (at 100\% isodose) in one case were delivered directly to the mammary gland without acute complications and with good cosmetic results. After an average of 30.8 months of follow up, no late sequelae were observed and the patients are free of disease.

Conclusion In patients previously irradiated for HD, ELIOT can avoid repeat irradiation of the whole breast, permit BCS and decrease the number of avoidable mastectomies.

\section{Introduction}

The risk of developing breast cancer after radiotherapy for Hodgkin's disease (HD) is well documented and is attributed to the incidental inclusion of portions of the breast in the portals used to irradiate the mediastinum with or without infraclavicular/axillary regions $[1,2]$. This increased risk depends on several patient and treatment factors, including radiation dose, radiation treatment field and age at treatment [3]. The estimated risk is also affected by the duration of follow up after radiotherapy and the method used to calculate risk [4]. Based on concern about possible severe sequelae arising after a high total cumulative dose to the breast, several authors $[5,6]$ have suggested mastectomy as the treatment of choice for breast cancer arising after radiotherapy for HD.

Few studies have been published whereby alternative therapies to mastectomy have been employed; they describe local excision alone, or interstitial brachytherapy and local excision followed by local field external beam radiotherapy [7-10].

In order to avoid a dangerously high total cumulative dose of radiotherapy to the whole breast, soft tissues of the thoracic wall, lung and heart, without rejecting the possibility of breast conserving surgery (BCS), we evaluated the potential of performing full-dose intraoperative radiotherapy with electrons

BCS = breast conserving surgery; ELIOT = intraoperative radiotherapy with electrons; EORTC = European Organization for Research and Treatment of Cancer; HD = Hodgkin's disease; MeV = mega-electron volts; $\mathrm{PBI}=$ partial-breast irradiation;PFR = postoperative fractionated radiotherapy; RTOG = Radiation Therapy Oncology Group. 
(ELIOT) in women with early breast cancer who had been previously irradiated for HD.

\section{Materials and methods}

Between July 1999 and April 2005, 756 breast cancer patients who were candidates for BCS received ELIOT as the sole radiation treatment in the European Institute of Oncology in Milan. Of these, 100 patients had been treated in the past within a preliminary validation phase I study [11,12] and 440 patients are currently in an institutional phase III ongoing randomized clinical trial, in which 21 Gy ELIOT (prescribed at $90 \%$ isodose) is prospectively compared with external postoperative fractionated radiotherapy (PFR) including elective treatment of the whole breast. Eligibility criteria for the ELIOT randomized trial included patients aged between 48 and 75 years affected by a unicentric breast invasive carcinoma with a maximum diameter of $2.5 \mathrm{~cm}$. Locally advanced tumors (T3 and T4), the presence of a contralateral synchronous or metachronous tumor, non-invasive carcinomas (including Paget's disease), other breast malignancies different from carcinoma, multifocality or multicentricity of the disease, previous surgical biopsy and previous oncological history are considered exclusion criteria, while a breast thickness superior to $3 \mathrm{~cm}$ is considered a technical contraindication, it being impossible to deliver energy of more than 9 mega-electron volts $(\mathrm{MeV})$ with the present ELIOT dedicated linac. No particular tumor breast locations are excluded from ELIOT, but the close proximity of the tumor to the skin and pectoral major muscle infiltration are considered relative contraindication for ELIOT. In fact, in these cases, the irradiation of the entire breast, including skin and pectoral major muscle, is mandatory. Finally, if the tumor is very close to the axilla, ELIOT is avoided due to the risk of irradiating the axillary nerves and vessels.

In a selected group of 216 invasive breast cancer patients who were candidates for BCS, and who had specifically asked for and signed informed consent for ELIOT or in whom PFR was not considered safe or feasible due to clinical reasons (e.g. severe cardiopathy, large scars from skin burns, vitiligo, geographic or social obstacles), ELIOT was performed outside the randomized trial. In this selected group of patients, only the tumor size (larger than $2.5 \mathrm{~cm}$ ), locally advanced disease, multifocality or multicentricity were considered exclusion criteria. Of these 216 patients, 6 were previously treated for $\mathrm{HD}$ and received mantle radiation (Table 1 ).

The breast cancer presentation of these six patients is described in Table 2. Five patients underwent BCS and radioguided sentinel lymph node biopsy according to the standard technique adopted at the European Institute of Oncology [13].

Table 1

\begin{tabular}{|c|c|c|c|c|}
\hline Patient no. & Age (years) & Diagnosis & Stage & Therapy \\
\hline 1 & 29 & $\mathrm{HD}, \mathrm{MC}$ & $\| \mathrm{A}$ & MOPP × 6, Mantle 36 Gy \\
\hline 2 & 28 & $\mathrm{HD}, \mathrm{NS}$ & IIB & MOPP $\times 4$, ABVD $\times 4$, Mantle 20 Gy \\
\hline 3 & 42 & $\mathrm{Had}$ & IIB & ABVD $\times 3$, Mantle 40 Gy \\
\hline 4 & 38 & $\mathrm{HD}, \mathrm{MC}$ & $\| A$ & MOPP × 6, Mantle 40 Gy \\
\hline 5 & 24 & $\mathrm{HD}, \mathrm{NS}$ & IIB & MOPP $\times 6$, Mantle 40 Gy \\
\hline 6 & 30 & $\mathrm{HD}, \mathrm{NS}$ & $\| A$ & MOPP $\times 4$, ABVD $\times 4$, Mantle 36 Gy \\
\hline
\end{tabular}

aNo histologic subtype determined. ABVD, adriamicine, bleomycin, vinblastine, dacarbazine; HD, Hodgkin's disease; MC, mixed cellularity; MOPP, nitrogen mustard, vincristine, procarbazine, prednisone; NS, nodular sclerosis.

Table 2

\begin{tabular}{lccl}
\hline $\begin{array}{l}\text { Presentation of breast cancer } \\
\text { Patient no. }\end{array}$ & Age (years) & Interval since radiation for HD (years) & ELIOT dose \\
\hline 1 & 35 & 16 & $21 \mathrm{~Gy}(90 \%$ isodose), $7 \mathrm{MeV}$ \\
2 & 42 & 14 & $17 \mathrm{~Gy}(100 \%$ isodose), $7 \mathrm{MeV}$ \\
3 & 50 & 8 & $21 \mathrm{~Gy}(90 \%$ isodose), $9 \mathrm{MeV}$ \\
4 & 50 & 12 & $21 \mathrm{~Gy}(90 \%$ isodose), $9 \mathrm{MeV}$ \\
5 & 34 & 10 & $21 \mathrm{~Gy}(90 \%$ isodose), $7 \mathrm{MeV}$ \\
6 & 39 & 9 & $21 \mathrm{~Gy}(90 \%$ isodose), $9 \mathrm{MeV}$ \\
\hline
\end{tabular}

HD, Hodgkin's disease; MeV, mega electron volts. 
Table 3

\begin{tabular}{|c|c|c|c|c|c|c|c|}
\hline Patient no. & Tumor site & $\mathrm{T}$ & $\mathrm{N}$ & G & ER, PgR & $\mathrm{KI} 67$ & PVI \\
\hline 1 & UO & $1 \mathrm{c}$ & $0(\mathrm{sn})$ & 2 & $15 \%, 25 \%$ & $11 \%$ & No \\
\hline 2 & $\mathrm{LI}$ & $1 \mathrm{c}$ & $0(\mathrm{sn})$ & 3 & $0 \%, 0 \%$ & $70 \%$ & No \\
\hline 3 & C & $1 \mathrm{c}$ (is) & 0 (sn) & 1 & $90 \%, 90 \%$ & $13 \%$ & No \\
\hline 4 & $S$ & $1 \mathrm{c}$ & $1 \mathrm{a}$ & 2 & $85 \%, 85 \%$ & $25 \%$ & No \\
\hline 5 & UO & 2 & $1 \mathrm{a}$ & 2 & $30 \%, 0 \%$ & $27 \%$ & Yes \\
\hline 6 & UO & $1 b$ & $0(s n)$ & 1 & $90 \%, 90 \%$ & $8 \%$ & No \\
\hline
\end{tabular}

T, tumor size; N, axillary lymph nodes; G, tumor grade; ER, estrogen receptors; PgR, progesterone receptors; KI67, proliferative index; C, central; is, extended intraductal component associated; LI, lower inner; PVI, perivascular invasion; S, superior; sn, sentinel node; UO, upper outer.

In four out of the five cases, the biopsy showed that the sentinel lymph nodes were free of metastasis, so complete axillary dissection was not performed. In one patient, due to the presence of clinically metastatic axillary nodes, a complete axillary dissection was performed directly.

The radio-surgical technique of the six ELIOT procedures did not differ from the 'classic' technique, which has been described previously [14] in patients not previously irradiated for HD.

To evaluate acute and late radiation morbidity, the Radiation Therapy Oncology Group (RTOG) and European Organization for Research and Treatment of Cancer (EORTC) scoring scheme [15] was applied on the first and seventh day of the radio-surgical treatment and every six months during follow up.

\section{Radiation therapy device}

The dedicated ELIOT machine (Novac7, Hitesys, Italy) is a miniaturized linear accelerator that can be moved by a robotic arm, docked in the operating room and fulfils the statutory requirements with respect to radiological protection. Additional barriers (from 5 to $15 \mathrm{~mm}$ lead) are provided for positioning around the operating table. A lead shield $(15 \mathrm{~cm}$ thick) is also placed under the surgical bed corresponding to the electron field (beam stopper). ELIOT delivers a single full-dose of radiation directly to the tumor bed after removal of the tumor. Based on the radiobiological models used to predict radiation effects (linear-quadratic surviving fraction or multitarget surviving fraction) [16], we can estimate that a dose of 60 Gy delivered at 2 Gy daily, which is the radiation dose required to control the microscopical residual disease after breast resection, is equivalent to a single fraction of 20 to 22 Gy when using an $\alpha / \beta$ ratio at $10 \mathrm{~Gy}$, typical for tumors and acute reacting tissues. Using the same equation, but calculating the tolerance of late responding tissues ( $\alpha / \beta$ ratio at $3 \mathrm{~Gy})$, this equivalent value increases to at least $110 \mathrm{~Gy}$. The linac does not produce photons, but only delivers electron beams at four different energy levels: 3, 5, 7 and $9 \mathrm{MeV}$ as nominal energies, corresponding to $4.5,5.2,6.5$ and $7.8 \mathrm{MeV}$ effective energies to the phantom surface, respectively. The depth of $80 \%$ isodose ranged between $13 \mathrm{~mm}$ ( $3 \mathrm{MeV}$, not used in clinical practice) and $24 \mathrm{~mm}(9 \mathrm{MeV})$.

In one patient, a total dose of 17 Gy (prescribed at $100 \%$ isodose) using electron beams (7 MeV energy) was delivered. In five patients, 21 Gy (prescribed at $90 \%$ isodose, 7 or $9 \mathrm{MeV}$ of energy) were administered.

\section{Results}

The biological characteristics of the tumors are shown in Table 3. Two patients received adjuvant chemotherapy with cyclophosphamide-methotrexate/5-fluorouracil, followed by tamoxifen $20 \mathrm{mg} /$ day for 5 years associated in one case with LHRH analogue for 2 years. One patient received adriamicin/ cyclophosphamide followed by tamoxifen $20 \mathrm{mg} /$ day for 5 years associated with $\mathrm{LHRH}$ analogue for 2 years. Three patients received tamoxifen $20 \mathrm{mg} /$ day for 5 years, associated in two cases with LHRH analogue for 2 years.

ELIOT was well tolerated in all patients without any unusual acute reactions (grade 0 according to the EORTC/RTOG acute radiation morbidity criteria). In the patients with longer follow up, no late sequelae were observed (grade 0 according to the EORTC/RTOG late radiation morbidity scoring scheme) and all women had an excellent cosmetic result. All the patients are free of disease after 53, 38, 29, 24, 23 and 17 months of follow up (average 30.8).

\section{Discussion}

Previous mantle radiotherapy for HD is considered a contraindication to BCS and radiotherapy [17]. This is based on concerns about possible severe sequelae arising from a high total cumulative dose, exceeding normal tissue tolerance, being delivered to the portions of the breast that have presumably already received radiation for the lymphoma, even though modifications of the breast gland over time render the exact calculation of the dose infeasible many years after radiation delivery. Most authors consider these patients at significant risk of complications (fibrosis, skin and soft tissue necrosis, rib 
fractures, potential lung and heart toxicities) [6] and do not candidate them for BCS and adjuvant radiotherapy. In contrast, other reports $[18,19]$ support BCS followed by PFR when breast cancer develops many years after radiotherapy for HD. At present, no consensus exists regarding the correct management of breast cancer after mantle irradiation for HD and, given the discordant results and the small number of women treated with BCS, mastectomy continues to be recommended as the standard treatment. To avoid a high total cumulative dose to portions of the breast or soft tissues of the thoracic wall, one of the conservative options is to treat just the tumor bed: the irradiation of a small volume of the breast and adjacent structures could allow the risk of complications to be minimized [7-10]. Therefore, over the past decade there has been increasing interest in a variety of radiation techniques designed to treat only the portion of the breast deemed to be at high risk for local recurrence [20]: these include brachytherapy implants, MammoSite applicator, intraoperative orthovoltage device, and 3D conformal or intensity-modulated external radiotherapy (partial-breast irradiation (PBI)). All these techniques have similar indications but different applications $[21,22]$. In particular, they differ in the source of radiation (for example, X-ray, Iridium, photons) and the amount of breast volume treated. Although 5 to 7 year outcome data on patients treated with PBI are now becoming available, many issues remain unresolved, including the clinical and pathological selection criteria of patients, radiation dose and fractionation, and how these relate to the standard fractionation for whole breast irradiation, appropriate target volume, local control within the untreated ipsilateral breast tissue, and overall survival. With a view to furnishing guidelines and clarifying the issues of major controversy, a workshop on PBI was held in Bethesda, in December 2002. The workshop report emphasized the importance of education and training with regard to the results of $\mathrm{PBI}$ as it becomes an emerging clinical treatment [23]. In particular, ELIOT, a new radiotherapeutic technique that delivers a single dose of radiation directly to the tumor bed during the conservative surgical treatment of early breast cancer, has been proposed for evaluation in randomized clinical trials as a possible alternative to standard PFR.

When in July 1999 we focused our interest on the use of intraoperative radiotherapy as an exclusive treatment in small unifocal infiltrating breast carcinomas, we considered that ELIOT could be specifically applied in all those situations in which PFR was not considered safe or feasible for various reasons (for example, severe cardiopathy, large hypertrophic scarring from skin burns, vitiligo, geographic or social obstacles) [24] and, in particular, in patients irradiated for HD. After our first preliminary report [25], ELIOT was proposed in six patients previously irradiated for HD. In all cases, the dose delivered and the energy of electron beams from ELIOT did not differ from those in the other 549 patients submitted to ELIOT; in one patient a total dose of $17 \mathrm{~Gy}$ (prescribed at $100 \%$ isodose) using electron beams at $7 \mathrm{MeV}$ energy and in five patients doses of $21 \mathrm{~Gy}$ (90\% isodose, 7 and $9 \mathrm{MeV}$ of energy) were delivered. The different electron energies administrated ( 7 or $9 \mathrm{MeV}$ ) are related to the different breast gland thickness.

The radio-surgical technique of the six ELIOT procedures did not differ from the 'classic' technique used for previously nonirradiated patients [14]. In particular, to ensure a good coverage of the target by the radiation dose and maximal protection of the normal tissues in the operative area, adequate preparation for irradiation of the portion of breast gland to undergo ELIOT is necessary. Protective devices are placed between the gland and the pectoral muscle; a dedicated lead disk $5 \mathrm{~mm}$ thick and an aluminium disk $4 \mathrm{~mm}$ thick, available in various diameters $(4,5,6,8,10 \mathrm{~cm})$ are commonly used. The wall protection is guaranteed both by the absorption properties of the lead and aluminium and the $9 \mathrm{~mm}$ outdistance created by the disks.

We scored the radiation morbidity according to the RTOG/ EORTC criteria [15]. ELIOT was well tolerated without any unusual acute reactions despite previous breast irradiation. We did not observe any ischemic or necrotic problems of the skin flap due to the careful sparing of the subcutaneous vessels during the mobilization of the residual breast around the tumor bed. No increased post-operative complications (pain, seroma, emathoma, infection) were observed in these six patients when compared to the overall group of ELIOT patients. The length of hospital stay was therefore not prolonged. The cosmetic outcome was also very good in all patients: no skin erythema was observed as a result of the complete removal of the skin from the radiation beam.

The follow up is too short (average 30.8 months) to evaluate late sequelae in these six re-irradiated patients but no complications were observed in the four patients with more than 2 years of follow up.

\section{Conclusion}

ELIOT dramatically reduces the radiation exposure of the normal tissues and, in particular, of the previously irradiated breast, avoiding a high total cumulative dose to the gland and to the soft tissues of the thoracic wall. In patients previously treated for HD, ELIOT permits BCS independently of the interval between mantle radiotherapy and breast surgery, without acute local complications, decreasing the number of avoidable mastectomies. A longer follow up is necessary to evaluate the incidence of radiation-induced sequelae and the local recurrence rate.

\section{Competing interests}

The author(s) declare that they have no competing interests.

\section{Authors' contributions}

$\mathrm{Ml}$ conceived the study, and participated in its design and coordination and drafted the manuscript, OG helped to draft 
the manuscript, PV participated in the coordination of the study, MC participated in the coordination of the study, AL participated in the design of the study, JS carried out patient follow up, GF carried out patient follow up, and RO and UV participated in the design of the study. All authors read and approved the final manuscript.

\section{Acknowledgements}

The authors wish to acknowledge the AIRC (Italian Association for Cancer Research) and the AICF (American Italian Cancer Foundation), which partially funded this research project.

\section{References}

1. Boivin JF, O'Brien K: Solid cancer risk after treatment of Hodgkin's disease. Cancer 1988, 61:2541-2546.

2. Tucker MA, Coleman CN, Cox RS: Risk of second cancers after treatment for Hodgkin's disease. N Engl J Med 1988, 318:76-81.

3. Tinger A, Wasserman TH, Klein EE, Miller EA, Roberts T, Piephoff JV, Kucik NA: The incidence of breast cancer following mantle field radiation therapy as a function of dose and technique. Int J Radiat Oncol Biol Phys 1997, 37:865-870.

4. Wolden SL, Lamborn KR, Cleary SF, Tate DJ, Donaldson SS: Second cancers following pediatric Hodgkin's disease. J Clin Oncol 1998, 16:536-544.

5. American College of Radiotherapy, American College of Surgeons, College of American Pathologists, Society of Surgical Oncology, Winchester DP, Cox JD: Standards for breast-conservation treatment. CA Cancer J Clin 1992, 42:134-162.

6. Wolden SL, Hancock SL, Carlson RW, Goffinet DR, Jeffrey SS, Hoppe RT: Management of breast cancer after Hodgkin's disease. J Clin Oncol 2000, 18:765-772.

7. Krishnan L, Jewell WR, Tawfik OW, Krishnan EC: Breast conservation therapy with tumor bed irradiation alone in a selected group of patients with stage I breast cancer. Breast J 2001, 7:91-96.

8. Perera F, Engel J, Holliday R, Scott L, Girotti M, Girvan D, Chisela $F$, Venkatesan V: Local resection and brachytherapy confined to the lumpectomy site for early breast cancer: a pilot study. $J$ Surg Oncol 1997, 65:263-267.

9. Baglan KL, Martinez AA, Frazier RC, Kini VR, Kestin LL, Chen PY, Edmundson G, Mele E, Jaffray D, Vicini FA: The use of high-doserate brachytherapy alone after lumpectomy in patients with early-stage breast cancer treated with breast-conserving therapy. Int J Radiat Oncol Biol Phys 2001, 50:1003-1011.

10. Vicini F, Kini VR, Chen P, Horwitz E, Gustafson G, Benitez P, Edmundson G, Goldstein N, McCarthy K, Martinez A: Irradiation of the tumor bed alone after lumpectomy in selected patients with early-stage breast cancer treated with breast conserving therapy. J Surg Oncol 1999, 70:33-40.

11. Veronesi U, Orecchia R, Luini A, Gatti G, Intra M, Veronesi $P$, Gatzemeier W, Ciocca M, Tosi G, Ivaldi G, et al:: Focalised intraoperative irradiation after conservative surgery for early stage breast cancer. The Breast 2001, 10(Suppl 3):84-89.

12. Veronesi U, Orecchia R, Luini $A$, Gatti $G$, Intra $M$, Zurrida $S$, Ivaldi G, Tosi G, Ciocca M, Tosoni A, De Lucia F: A preliminary report of intraoperative radiotherapy (IORT) in limited-stage breast cancers that are conservatively treated. Eur J Cancer 2001, 37:2178-2183.

13. Veronesi U, Paganelli G, Viale G, Galimberti V, Luini A, Zurrida S, Robertson C, Sacchini V, Veronesi P, Orvieto E, et al:: Sentinel lymph node biopsy and axillary dissection in breast cancer: results in a large series. J Nat/ Cancer Inst 1999, 91:368-373.

14. Intra M, Gatti G, Luini A, Galimberti V, Veronesi $P$, Zurrida S, Frasson A, Ciocca M, Orecchia R, Veronesi U: Surgical technique of intraoperative radiotherapy in conservative treatment of limited-stage breast cancer. Arch Surg 2002, 137:737-740.

15. Cox JD, Stetx J, Pajak TF: Toxicity criteria of the Radiation Therapy Oncology Group (RTOG) and the European Organization for Research and Treatment of Cancer (EORTC). Int J Radiat Oncol Biol Phys 1995, 31:1341-1346.
16. Tucker SS, Thames HD, Taylor JM: How well is the probability of tumor cure after fractionated irradiation described by Poisson statistics. Radiat Res 1990, 124:273-282.

17. The Steering Committee on Clinical Practice Guidelines for the Care and Treatment of Breast Cancer: Breast radiotherapy after breast-conserving surgery. CMAJ 1998, 158(Suppl 3):S35-42.

18. Aref I, Cross P: Conservative surgery and radiation therapy for early stage breast cancer after previous mantle radiation for Hodgkin's disease. Br J Radiol 2000, 73:905-906.

19. Deutsch M, Gerszten K, Bloomer W, Avisar E: Lumpectomy and breast irradiation for breast cancer arising after previous radiotherapy for Hodgkin's disease. Am J Clin Oncol 2001, 24:33-34.

20. Veronesi U, Marubini E, Mariani L, Galimberti V, Luini A, Veronesi $P$, Salvadori B, Zucali R: Radiotherapy after breast-conserving surgery in small breast carcinoma: long-term results of a randomized trial. Ann Oncol 2001, 12:997-1003.

21. Dickler A, Kirk MC, Chu J, Nguyen C: The MammoSitetrade mark breast brachytherapy applicator: A review of technique and outcomes. Brachytherapy 2005, 4:130-136.

22. Weed DW, Edmundson GK, Vicini FA, Chen PY, Martinez AA Accelerated partial breast irradiation: A dosimetric comparison of three different techniques. Brachytherapy 2005, 4:121-129.

23. Wallner $\mathrm{P}$, Arthur D, Bartelink $\mathrm{H}$, Connolly J, Edmundson G, Giuliano A, Goldstein N, Hevezi J, Julian T, Kuske R, et al:: Workshop on partial breast irradiation: state of the art and the science, Bethesda, MD, December 8-10, 2002. J Natl Cancer Inst 2004, 96:175-184.

24. Intra $\mathrm{M}$, Orecchia $\mathrm{R}$, Veronesi U: Intraoperative radiotherapy: the debate continues. Lancet Oncol 2004, 5:340.

25. Intra $M$, Leonardi MC Gatti G, Vento AR, Ciocca M, Veronesi $P$ Bassani G, Dos Santos GR, Rodriguez J, Luini A, et al.: Intraoperative radiotherapy during breast conserving surgery in patients previously treated with radiotherapy for Hodgkin's disease. Tumori 2004, 90:13-16. 